\title{
Enantioselective organocatalytic reduction of $\beta$-trifluoromethyl nitroalkenes: an efficient strategy for the synthesis of chiral $\beta$-trifluoromethyl amines.
}

Elisabetta Massolo, ${ }^{\mathrm{a}}$ Maurizio Benaglia, ${ }^{\mathrm{a} *}$ Manuel Orlandi, ${ }^{\mathrm{a}}$ Sergio Rossi ${ }^{\mathrm{a}}$ and Giuseppe Celentano ${ }^{\mathrm{b}}$

'Dipartimento di Chimica, Universita' degli Studi di Milano, via Golgi 19, 20133 Milano, Italy; ${ }^{b}$ Dipartimento di Scienze Farmaceutiche, Università degli Studi di Milano, Via Mangiagalli, 25, Milano, Italy

Corresponding author: Maurizio Benaglia, tel. +390250314171; fax: +390250314159; e-mail: maurizio.benaglia@unimi.it

\begin{abstract}
An efficient organocatalytic stereoselective reduction of $\beta$-trifluoromethyl-substituted nitroalkenes, mediated by 3,5-dicarboxylic esters-dihydro pyridines (Hantzsch ester type), has been successfully developed. A multifunctional thiourea-based $(S)$-valine derivative was found to be the catalyst of choice, promoting the reaction in up to $97 \%$ ee. The methodology has been applied to a wide variety of substrates, leading to the formation of differently substituted precursors of enantiomerically enriched $\beta$-trifluoromethyl amines. The mechanism of the reaction and the mode of action of the metal-free catalytic species were computationally investigated; on the basis of DFT transition states (TS) analysis, a model of stereoselection was also proposed.
\end{abstract}

Keywords: nitroalkenes / chiral fluorinated amines / reduction / bifunctional catalyst / trifluoromethyl derivatives

The introduction of fluorinated residues in a bioactive molecule may have a strong impact on its effectiveness, simultaneously modulating electronic, lipophilic and steric parameters, critically influencing both the pharmacodynamic and pharmacokinetic properties.[1] Many drugs are characterized by the presence of $\mathrm{CF}_{3}$ group, as Efavirenz, used against $\mathrm{HIV}$ infection, Telcalgepant, employed in the treatment of the neurovascular disorder migraine and Prozac (Figure 1). Among several trifluoromethylated compounds known in medicinal chemistry, $\alpha$ - and $\beta$-trifluoromethylamine units are major components found in this class of bioactive species (Figure 1).[2] Despite the 
great interest in the topic and progress in the field, highly stereochemically efficient catalytic methods for the synthesis of chiral fluorinated amines are still deeply needed.[3]<smiles>CCC1CC1C#CC1(C(F)(F)F)OC(=O)Nc2ccccc21</smiles>

Efavirenz<smiles>CNCCC(Oc1ccc(C(F)(F)F)cc1)c1ccccc1</smiles>

Prozac ${ }^{\circledR}$<smiles>O=C(N[C@H]1CC[C@@H](c2cccc(F)c2F)CN(CC(F)(F)F)C1=O)N1CCC(n2c(=O)[nH]c3ncccc32)CC1</smiles>

Telcalgepant<smiles>O=C(O)Cc1cc(Cl)c2c(c1)CCC(C(F)(F)F)N2</smiles>

antirheumatic agent<smiles>CNCCCOc1cc(F)c(-c2c(Cl)nc3ncnn3c2N[C@@H](C)C(F)(F)F)c(F)c1</smiles><smiles>O=C(O)C[C@@H](N[C@@H](Br)CS)C(F)(F)F</smiles>

neutral endopeptidase inhibitor<smiles>[R]OC(=O)C([R])NC(=O)C(CNC(=O)C([R])N=P)C(F)(F)F</smiles>

Peptidomimetics<smiles>CO[SH](=O)(OC)c1ccc(-c2ccc([C@H](N[C@@H](CC(C)(C)F)C(=O)NC3(C#N)CC3)C(F)(F)F)cc2)cc1</smiles>

Odanacatib, MK-08222, Cathepsin K inhibitor

Figure 1. Some biologically active trifluromethylated compounds.

After focusing on the preparation of chiral $\alpha$-trifluoromethyl-amine, by trichlorosilanemediated enantioselective catalytic reduction of trifluoromethyl ketoimines, ${ }^{[4]}$ we turned our attention to chiral $\beta$-trifluoromethyl-amines. Recent works on innovative, non stereoselective, methods of trifluoromethylation to generate $\beta$-trifluoromethyl-substituted aza-derivatives clearly testify for the great interest in the preparation of this class of compounds. [5] However, really few strategies are available for the stereoselective synthesis of enantiopure $\beta$-trifluoromethyl-amines. In 2013, a chemo- and enantioselective $\mathrm{CF}_{3} \mathrm{SiMe}_{3}$ addition to $\alpha$-imino ketones promoted by Cinchona derived ammonium salts was reported (up to $71 \%$ ee). ${ }^{[6]}$ In the same year, based on the seminal contributions by MacMillan group, ${ }^{[7]}$ the first visible light-driven intermolecular aminotrifluoromethylation of alkenes was developed, as efficient and regioselective one-step access to a variety of $\beta$-trifluoromethylamides in up to $82 \%$ yield and $78 \% \mathrm{dr} .^{[8]}$

An alternative strategy to obtain chiral trifluoromethyl derivatives relies on the stereoselective transformation of trifluoromethylated prochiral, readily available substrates. Fluorinated 
nitroalkenes represent an obvious entry for the synthesis of $\beta$-trifluoromethyl-amino derivatives. They have been widely used in combination with a chiral reactant partner to diastereoisomerically produce $\beta$-nitro-trifluoromethylated products; typical examples include the synthesis of trifluoromethylated peptide analogues, using enantiopure $\alpha$-amino acids as nucleophiles.[9] Fluorinated nitroolefines have been also employed in organocatalytic Michael reactions with aldehydes, ${ }^{[10]}$ intermolecular oxa-Michael addition of oximes ${ }^{[11]}$ and 3-alkylidene oxindoles, ${ }^{[12]}$ and in the addition of indole ${ }^{[13]}$ and $\beta$-dicarbonyl compounds. [14]

However, as far as we know, no examples of enantioselective organocatalytic reduction of trifluoromethylated nitroalkenes are known. Here we wish to report our preliminary investigation on the synthesis of enantiomerically enriched- $\beta$-trifluoromethyl nitroolefins, via organocatalyzed addition of Hantzsch ester-type reducing agents to fluorinated nitroalkenes. Considering that the starting materials are readily, and often commercially, available, trifluoromethyl ketones the methodology offers an easy, catalytic and practical entry to chiral $\beta$-trifluoromethyl-amines (Scheme 1).
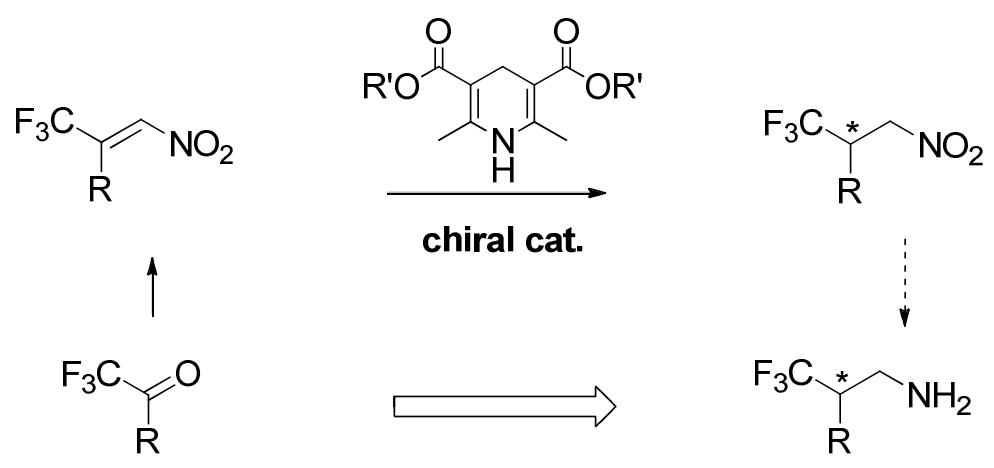

Scheme 1. Organocatalytic approach to the synthesis of chiral $\beta$-trifluoromethyl-amines.

In 2007, List and co-workers published the organocatalyzed stereoselective reduction of nitroalkenes affording the corresponding enantiomerically enriched nitroalkanes in high yields and up to $96 \%$ enantiomeric excess, the most efficient catalyst featuring a thiourea moiety linked to the diethylamide of $(S)$-tert-leucine and to the $N$-pyrrole derivative of $(R, R)$-diaminocyclohexane.[15] Based on this previous work we have preliminary explored a variety of bifunctional, thiourea-based molecules as catalyst for the reduction of trifluoromethylated nitroolefins (Figure 2). ${ }^{[16]}$ Catalysts 111 were easily synthesized in four steps through conversion of the $N$-Boc amino acid to the corresponding amide, followed by $N$-Boc-deprotection, generation of the isothiocyanate group and reaction with the proper 1,2-diaminocyclohexane derivative. 
The reduction of $\beta$-trifluoromethyl- $\beta$-nitrostyrene $\mathbf{1 2}$ was selected as model reaction and typically performed at $25^{\circ} \mathrm{C}$ for 20 hours in the presence of a stoichiometric amount of Hantzsch ester $\mathbf{A}$ and a catalytic amount (10 mol\%) of the organocatalysts, to afford the expected product $\mathbf{1 3}$ (Scheme 2). The results of this preliminary screening are detailed in Table 1.<smiles>CN(C)C(=O)[C@H](NC(=S)N[14C]1CCCC[14C]1(C)C)C(C)(C)C</smiles>

1<smiles>CN(C)C(=O)[C@H](NC(=S)N[C@@H]1CCCC[C@@H]1[N+](C)(C)F)C(C)(C)C</smiles>

4<smiles>CC(C)[C@H](NC(=S)N[14C]1CCCC[14C]1=O)C(=O)N(C)C</smiles>

7<smiles>CN(C)C(=O)[C@H](NC(=S)N[C@H]1CCCC[C@@H]1Cl)C(C)(C)C</smiles>

2<smiles>CN(C)C(=O)[C@H](NC(=S)N[14C]1CCCC[14C]1N1C(=O)c2ccccc2C1=O)C(C)(C)C</smiles>

5<smiles>CC(C)[C@H](NC(=S)N[C@H]1CCCC[C@H]1Cl)C(=O)N(C)C</smiles>

8<smiles>CN(C)C(=O)[C@H](NC(=S)N[14C]1CCCC[14CH2]1)C(C)(C)C</smiles>

3<smiles>CCN(CC)C(=O)[C@H](NC(=S)N[14C]1CCCC[14C@@H]1n1c(C)ccc1C)C(C)(C)C</smiles>

6<smiles>Cc1ccc(C)n1[C@@H]1CCCC[C@@H]1NC(=S)N[C@@H](C(=O)N(C)C)C(C)C</smiles>

9<smiles>Cc1ccc(C)n1[14C]1CCCC[14C]1NC(=S)N[C@@H](C(=O)N(Cc1ccccc1)Cc1ccccc1)C(C)C</smiles>

10<smiles></smiles>

11

Figure 2. A few selected chiral organocatalysts employed in the present study.<smiles>CCOC(=O)C1=C(C)NC(C)=C(C(=O)OCC)C1C(=O)OCC</smiles>

Scheme 2. Organocatalytic reduction of $\beta$-trifluoromethyl-nitrostyrene 
Table 1. Preliminary studies on the catalytic reduction of $\mathbf{1 2}$ with organocatalysts 1-11.

\begin{tabular}{cccc}
\hline Entry & Cat. & Conv. $(\%)^{\mathrm{a}}$ & e.e. $(\%)^{\mathrm{b}}$ \\
\hline 1 & $\mathbf{1}$ & 60 & $<5$ \\
3 & $\mathbf{2}$ & $>99$ & rac. \\
4 & $\mathbf{3}$ & 60 & 13 \\
5 & $\mathbf{4}$ & 83 & rac. \\
6 & $\mathbf{6}$ & 85 & 38 \\
7 & $\mathbf{7}$ & $>99(99)^{\mathrm{c}}$ & 59 \\
8 & $\mathbf{8}$ & $>99$ & 43 \\
9 & $\mathbf{9}$ & $95(93)^{\mathrm{c}}$ & 81 \\
11 & $\mathbf{1 1}$ & 80 & 57 \\
\hline 10 & $\mathbf{1 0}$ & $>99(98)^{\mathrm{c}}$ & 77 \\
\hline & & & 59 \\
\hline
\end{tabular}

${ }^{a}$ Reaction run in deuterated benzene at RT; conversion determined by ${ }^{1} \mathrm{H}$ and ${ }^{19} \mathrm{~F} N \mathrm{NR} ;{ }^{b}$ Enantiomeric excess determined by HPLC on chiral stationary phase (see Supporting Information for details); ${ }^{c}$ In brackets isolated yields after chromatographic purification.

In looking for the best catalyst, we systematically investigated how the different parts constituting the skeleton of these thiourea-based structures influence their activity and stereoselectivity. Thus, the modification of the diaminocyclohexane $N$-substituents clearly showed that an acceptable level of enantiocontrol could be achieved only with sterically hindered residues on the amino group (entries 1-4 vs entries 5-6). In particular, a pyrrole ring proved to be more effective than a phtalimide in shielding one of the two enantiotopic faces of the nitroalkene, probably due to the presence of the 2,5-dimethyl substituents, able to extend the influence of the heterocycle ring on the region of space just close to the site where the substrate is supposed to be coordinated to the thiourea residue of the catalyst (Figure 3, see below, Figure 5, for further 
considerations based on computational studies). However with catalyst $\mathbf{6}$ a modest enantioselectivity was obtained.

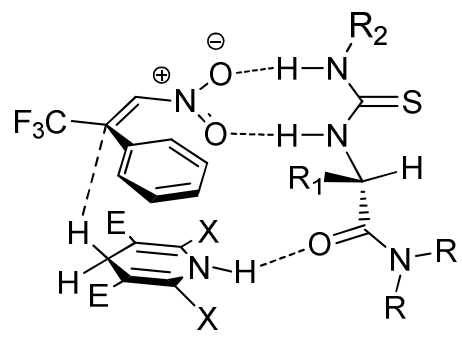

Figure 3. Proposed mode of action of the bifunctional thiourea-based catalyst.

Therefore we decided to look at the aminoacid portion of the catalyst; it was observed that, when replacing tert-leucine with valine, higher e.e. were obtained. Entries 7-8 of Table 1 demonstrated the combination $(S)$-valine and $(R, R)$.diaminocyclohexane to be the match pair, that guarantees higher e.e.. The 2,5-dimethyl derivative 9 was able to promote the reduction of $\beta$ trifluoromethyl nitrostyrene at RT in $81 \%$ enantioselectivity, to afford $(R)$-2-trifluoromethyl-2phenyl-nitroethane $\mathbf{1 3}$ in $95 \%$ yield; $N, N$-dibenzyl substituents on the amide function (catalyst 10) afforded only slightly lower e.e. with respect to derivative 9.

Once compounds $\mathbf{9}$ and $\mathbf{1 0}$ have been identified as the most promising catalysts, a screening of reaction conditions was carried out. When temperature was lowered to $0^{\circ} \mathrm{C}$, a diminished chemical activity was observed but no significant improvement in enantiocontrol (entries 1,2 of Table 2). To improve the reaction rate and to allow to perform the reduction at lower temperature, $t$-butyl ester derivative $\mathbf{B}$ (Figure 4), known to be a more active reducing agent,[17] was employed. In dichloromethane (entries 3-6) neither at $0^{\circ} \mathrm{C}$ nor at $-50^{\circ} \mathrm{C}$ higher ee were achieved; however, by running the reaction in toluene, an increase of the enantioselectivity was observed for lower reaction temperatures; in the presence of the Hantzsch type ester $\mathbf{B}$ at $-50^{\circ} \mathrm{C}$, the stereoselectivity was improved up to $87 \%$ e.e. with catalyst $\mathbf{9}$ and up to $93 \%$ e.e. with catalyst $\mathbf{1 0}$ (entries 9-10, Table 2). Reductions in polar or protic solvents led to the products with low stereocontrol, while hexanes proved to be a suitable solvent for the reaction: with catalyst 9 at $-50^{\circ} \mathrm{C}$, up to $83 \%$ e.e. was reached (entry 15).<smiles>CCOC(=O)C1=C(C)NC(C)=C(C(=O)OCC)C1</smiles>

A<smiles>CCC(C)OC(=O)C1=C(C)NC(C)=C(C(=O)OCC(C)(C)C)C1</smiles>

B<smiles>COC(=O)C1=C(C)NC(C)=C(C(=O)OC)C1</smiles>

C

Figure 4. Different reducing agents. 
Table 2. Screening of experimental conditions in the organocatalyzed reduction of $\mathbf{1 2 .}$

\begin{tabular}{|c|c|c|c|c|c|c|}
\hline Entry & Cat. & Solvent & $\mathrm{T}$ & $\begin{array}{l}\text { Hantzsch } \\
\text { ester }\end{array}$ & Conv. $(\%)^{\mathrm{a}}$ & e.e. $(\%)^{\mathrm{b}}$ \\
\hline 1 & 7 & $\mathrm{CH}_{2} \mathrm{Cl}_{2}$ & $0^{\circ} \mathrm{C}$ & $\mathbf{A}(\mathrm{COOEt})$ & 50 & 60 \\
\hline 2 & 9 & $\mathrm{CH}_{2} \mathrm{Cl}_{2}$ & $0^{\circ} \mathrm{C}$ & $\mathbf{A}(\mathrm{COOEt})$ & 60 & 80 \\
\hline 3 & 9 & $\mathrm{CH}_{2} \mathrm{Cl}_{2}$ & $0^{\circ} \mathrm{C}$ & $\mathbf{B}(\mathrm{COO} t \mathrm{Bu})$ & $>99$ & 78 \\
\hline 4 & 9 & $\mathrm{CH}_{2} \mathrm{Cl}_{2}$ & $-15^{\circ} \mathrm{C}$ & $\mathbf{B}(\mathrm{COO} t \mathrm{Bu})$ & $>99$ & 77 \\
\hline 5 & 10 & $\mathrm{CH}_{2} \mathrm{Cl}_{2}$ & $-15^{\circ} \mathrm{C}$ & $\mathbf{B}(\mathrm{COO} t \mathrm{Bu})$ & $>99$ & 74 \\
\hline 6 & 9 & $\mathrm{CH}_{2} \mathrm{Cl}_{2}$ & $-50^{\circ} \mathrm{C}$ & $\mathbf{B}(\mathrm{COO} t \mathrm{Bu})$ & $>99$ & 77 \\
\hline 7 & 9 & toluene & RT & $\mathbf{B}(\mathrm{COO} t \mathrm{Bu})$ & $>99$ & 71 \\
\hline 8 & 10 & toluene & RT & $\mathbf{B}(\mathrm{COO} t \mathrm{Bu})$ & $>99$ & 81 \\
\hline 9 & 9 & toluene & $-50{ }^{\circ} \mathrm{C}$ & $\mathbf{B}(\mathrm{COO} t \mathrm{Bu})$ & 61 & 87 \\
\hline 10 & 10 & toluene & $-50{ }^{\circ} \mathrm{C}$ & $\mathbf{B}(\mathrm{COO} t \mathrm{Bu})$ & 71 & 93 \\
\hline 11 & 9 & THF & $0^{\circ} \mathrm{C}$ & $\mathbf{B}(\mathrm{COO} t \mathrm{Bu})$ & $>99$ & 9 \\
\hline 12 & 9 & EtOH & $0^{\circ} \mathrm{C}$ & $\mathbf{B}(\mathrm{COO} t \mathrm{Bu})$ & $>99$ & 6 \\
\hline 13 & 9 & hexanes & $0^{\circ} \mathrm{C}$ & $\mathbf{B}(\mathrm{COO} t \mathrm{Bu})$ & $>99$ & 80 \\
\hline 14 & 10 & hexanes & $-50^{\circ} \mathrm{C}$ & $\mathbf{B}(\mathrm{COOtBu})$ & 50 & 71 \\
\hline 15 & 9 & hexanes 2 & $-50^{\circ} \mathrm{C}$ & $\mathbf{B}(\mathrm{COO} t \mathrm{Bu})$ & 70 & 83 \\
\hline
\end{tabular}

${ }^{a}$ Conversion determined by ${ }^{1} \mathrm{H}$ and ${ }^{19} \mathrm{~F}$ NMR $;{ }^{b}$ Enantiomeric excess determined by HPLC on chiral stationary phase (see Supporting Information for details).

The generality of the method was finally investigated (Scheme 3); differently 2-aryl and 2alkyl substituted 3,3,3-trifluoro-1-nitropropene derivatives 14a-g have been prepared and reacted with dihdropyridine $\mathbf{B}$ to afford the corresponding chiral trifluoromethyl nitroalkanes $\mathbf{1 5 a} \mathbf{a}$, in the presence of $10 \% \mathrm{~mol}$ eq. of catalyst $\mathbf{1 0}$ in toluene, typically at $-50^{\circ} \mathrm{C}$. Some selected results are reported in Table 3. 


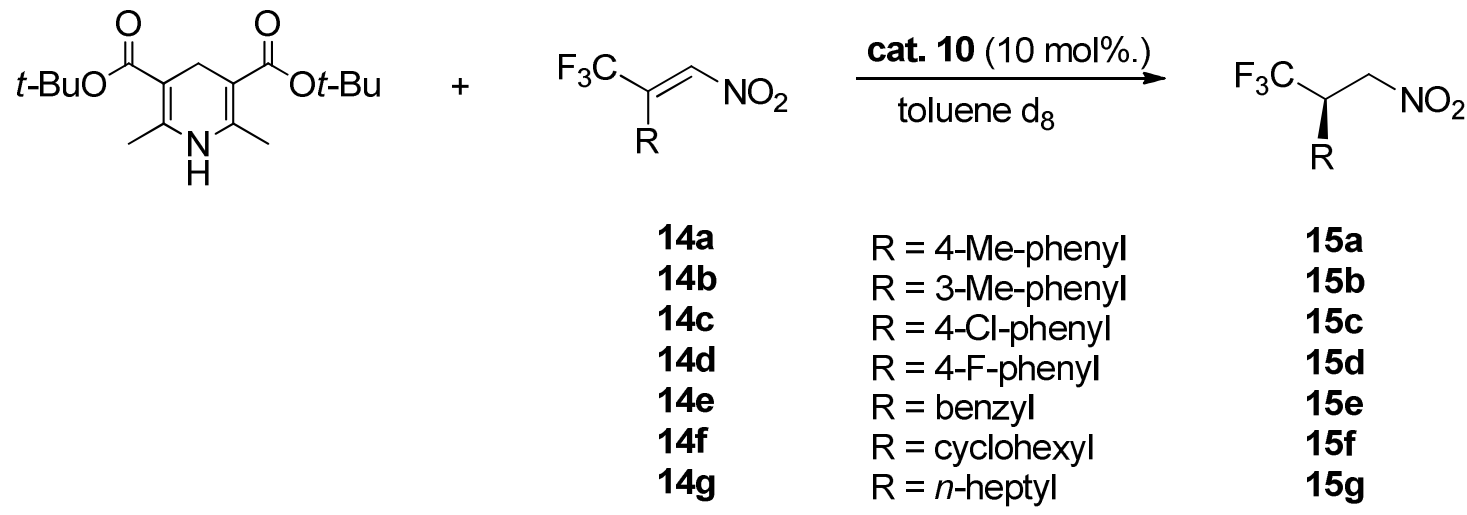

Scheme 3. Organocatalytic reduction of $\beta$-trifluoromethyl nitroalkenes 14a-g.

Table 3. General applicability of the organocatalyzed reduction of fluorinated nitroolefins. ${ }^{a}$

\begin{tabular}{|c|c|c|c|c|}
\hline entry & Substrate & Time (h) & Conv. $(\%)^{\mathrm{b}}$ & e.e. ${ }^{c}$ \\
\hline 1 & & 36 & 81 & 83 \\
\hline 2 & & 36 & 75 & 73 \\
\hline 3 & & 20 & 85 & 81 \\
\hline 4 & & 20 & 81 & 90 \\
\hline 5 & & 20 & 89 & 90 \\
\hline 6 & & 20 & 80 & 97 \\
\hline 7 & & 36 & 75 & 93 \\
\hline
\end{tabular}


${ }^{a}$ Reaction run in deuterated toluene, with 10 mol\% of catalyst and 1.3 mol equivalents of reducing agent $\boldsymbol{B} ;{ }^{b}$ Conversion determined by ${ }^{1} \mathrm{H}$ and ${ }^{19} \mathrm{~F} N M R ;{ }^{c}$ Enantiomeric excess determined by HPLC on chiral stationary phase (see Supporting Information for details).

The reduction of differently substituted 2-aryl-2-trifluoromethyl nitroalkenes has been successfully accomplished, either on substrates featuring electron-donating groups or electronwithdrawing residues; enantioselectivities usually higher than $80 \%$ and up to $90 \%$ were obtained (see entries 1-4, Table 3).

Even better results were achieved with 2-alkyl-substituted fluorinated nitroalkenes 14e-g; with benzyl derivative $\mathbf{1 4} \mathbf{e}$ the reduction mediated by catalyst $\mathbf{1 0}$ afforded the expected nitroalkane 15e in $90 \%$ e.e. Excellent results were obtained in the reduction of alkyl-nitroalkenes $\mathbf{1 4 f - g}$ that afforded products $\mathbf{1 5 f}$ and $\mathbf{1 5 g}$ in $97 \%$ and $93 \%$ e.e., respectively.

Possible extension of this reaction to $\alpha, \beta$-disubstituted- $\beta$-trifluoromethylnitroalkenes has also been preliminary investigated (Scheme 4). It is worth mentioning that the stereoselective reduction of nitrostyrene derivatives featuring an $\alpha$-substituent is still considered a challenging transformation, that requires a controlled protonation step ${ }^{[18]}$ and leads to the formation of a rather labile stereocentre; indeed, at the best of our knowledge, no organocatalytic example has been reported so far.[19]<smiles>CCCCOC(=O)C1=C(C)NC(C)=C(C(=O)OCC)C1</smiles><smiles>[R]/C(=C(\C)C(F)(F)F)[N+](=O)[O-]</smiles>

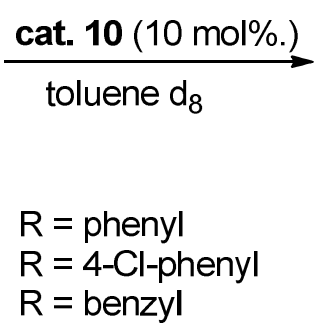<smiles>[R]C(C(C)C(F)(F)F)[N+](=O)[O-]</smiles>

$$
\begin{aligned}
& 16 a \\
& 16 b \\
& 16 c
\end{aligned}
$$$$
\mathrm{R}=4-\mathrm{Cl}-\text { phenyl }
$$

$17 a$ $17 b$ $17 \mathrm{c}$

Scheme 4. Reduction of $\alpha$-substituted- $\beta$-trifluoromethyl nitroalkenes 16a-c.

Substrates were obtained as differently enriched mixture of isomers that showed to be not configurationally stable and involved in a equilibrium. ${ }^{[20]}$ Due to this equilibration, H-H NOESY experiments were not decisive for attributing the $E / Z$ configuration; however computational analysis shown the $E$-isomer to be slightly more stable that $Z$-isomer (although by less than 2 kcals mol, see the Supporting Information). However, it is important to note that almost identical results in terms of yield, d.r. and e.e. were obtained in the enantioselective reduction of 16, independently from the diastereoisomeric ratio of the starting nitroalkene. 
The $\beta$-trifluoromethyl- $\alpha$-methyl-substituted nitro alkanes 17a-c were obtained in modest yields and low diastereoisomeric ratio, but with an appreciable level of enantioselectivity, typically about $60-70 \%$ e.e. for both isomers, and up to $77 \%$ e.e. (Table 4). Further experiments are necessary to determine the configuration of these novel fluorinated nitroalkanes, featuring two stereocenters. Follow-up studies will be undertaken to design and develop a stereoselective catalytic system better suited for this transformation.

Table 4. Organocatalyzed reduction $\alpha$-substituted- $\beta$-trifluoromethyl nitroalkenes. ${ }^{\text {a }}$

${ }^{a}$ Reaction run in deuterated toluene, with 10 mol\% of catalyst and 1.3 mol equivalents of reducing

\begin{tabular}{|c|c|c|c|c|c|c|}
\hline Entry & Substrate & $\begin{array}{l}\text { E/Z ratio } \\
\text { starting } \\
\text { material }\end{array}$ & React. T & $\operatorname{conv}^{\mathrm{b}}$ & $\mathrm{dr}^{\mathrm{b}}$ & $e^{c}$ \\
\hline 1 & & 71:29 & $0^{\circ} \mathrm{C}, \mathrm{t} 48 \mathrm{~h}$ & $20 \%$ & $58: 42$ & $\begin{array}{c}45 \%- \\
51 \%\end{array}$ \\
\hline 2 & & 71:29 & $25^{\circ} \mathrm{C}$ & $51 \%$ & $60: 40$ & $\begin{array}{c}67 \% \\
70 \%\end{array}$ \\
\hline 3 & & 95:5 & $25^{\circ} \mathrm{C}$ & $57 \%$ & $60: 40$ & $\begin{array}{c}65 \% \\
66 \%\end{array}$ \\
\hline 4 & & $54: 46$ & $25^{\circ} \mathrm{C}$ & $66 \%$ & $64: 36$ & $\begin{array}{r}77 \%- \\
67 \%\end{array}$ \\
\hline 5 & & $90: 10$ & $25^{\circ} \mathrm{C}$ & $42 \%$ & $62: 38$ & $\begin{array}{l}<5 \% \\
<5 \%\end{array}$ \\
\hline
\end{tabular}

agent $\boldsymbol{B} ;{ }^{b}$ Conversion and diastereoisomeric ratio determined by ${ }^{1} \mathrm{H}$ and ${ }^{19} \mathrm{~F} N M R ;{ }^{c}$ Enantiomeric excess determined by HPLC on chiral stationary phase (see Supporting Information for details).

In order to establish the absolute configuration of the reduction products, 15e was transformed by hydrogenation into the corresponding $\beta$-trifluoromethyl amine $\mathbf{1 8}$, that was converted in the known $N$-benzyl derivative $19,{ }^{[21]}$ thus determining the absolute configuration of the major isomer to be $R$ (Scheme 5).

Scheme 5. Determination of absolute configuration of product $\mathbf{1 5 e .}$ 


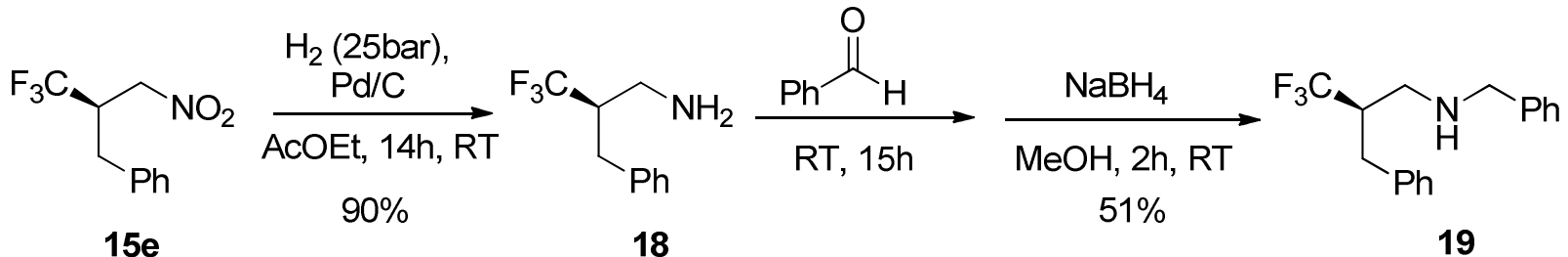

The different behaviour of tert-leucine derivative $\mathbf{6}$ and of the valine-based catalyst 9 was computationally investigated. The Transition States (TSs) leading to the formation of both $R$ - and $S$ 13, for the reaction with both catalysts 6 and 9, have been located at a B3LYP/6-31G(d) level of theory; finer electronic energies have successively been obtained increasing the basis set up to 6/311+(2df,2pd) with two different functionals: B3LYP ${ }^{[22]}$ and M062X.[23]

Figure 5. B3LYP/6-31G(d) geometries of the TSs for catalyst 9. In the "balls and springs" pictures, the COOMe groups of the Hantzsch ester are reported in "transparent" fashion; non-participating hydrogens are omitted for clarity. Below a comparison between catalyst $\mathbf{6}$ and $\mathbf{9}$ is reported.
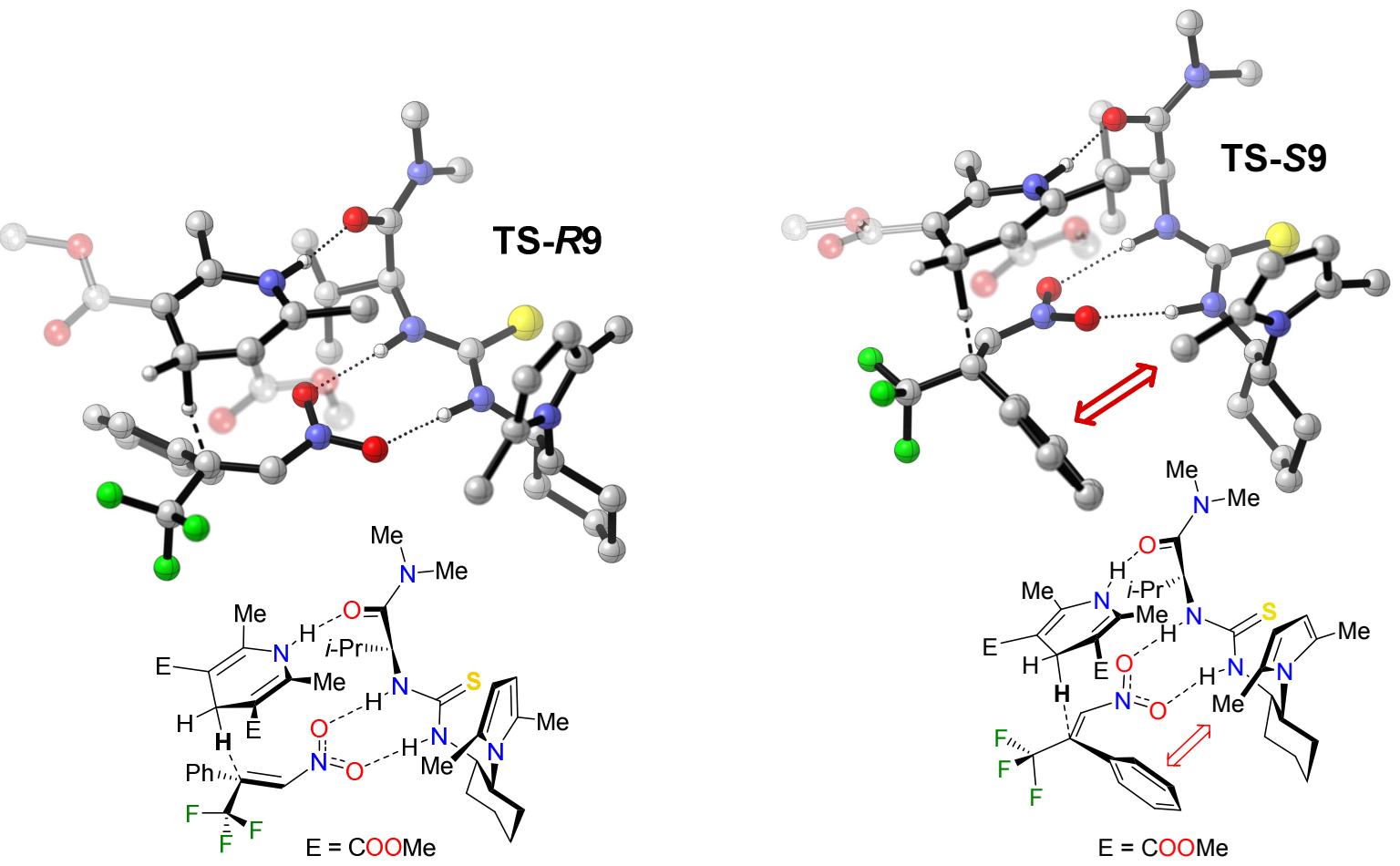

Preliminary conformational analysis on the catalysts underlined a very rigid structure: only three conformations for catalyst 9 and a unique conformation for catalyst $\mathbf{6}$ are energetically allowed. The selected TSs have been found, assuming the coordination of the nitro group to the thiourea moiety and of the Hantzsch ester NH group to the catalyst carboxyamide group (Figure 5). 
The methyl substituted Hantzsch ester $\mathbf{C}$ (see Figure 4) was used to reduce possible conformations of the system. In the tables and figures below, the notation TS-S9 refers to the TS of catalyst 9 leading to $(S)$ isomer.

In the case of catalyst 9 , a first inspection of the two TSs clearly highlights the role of the pyrrole moiety, that exerts in TS-S9 a repulsive interaction on the phenyl group of the nitroalkene, thus disfavouring the formation of the $(S)$-enantiomer. Additionally, a deeper look at TS-S9 and TS-R9 shows that upon the coordination of the substrate to the thiourea, the nitroolefin C2 electrophilic carbon in TS-S9 is closer to the bulky diaminocyclohexane moiety than in TS-R9. Therefore the reducing agent, in releasing the hydride, is forced in a hindered zone where its ester group repulsively interacts with the 2,5-methyl pyrrol substituents, thus further favouring TS-R9 (see Figure 5).

On the other hand, in the attempt to understand and compare the behaviour of catalysts 6 and 9, it should be noted that in TS-R of both catalysts a further repulsive interaction may occur between the phenyl ring and $i$-Pr or $t$-Bu groups. The competition between this two negative interactions seems to be responsible for the worst behaviour of catalyst $\mathbf{6}$ with respect to catalyst $\mathbf{9}$, where the less hindered $i$-Pr moiety may avoid a destabilizing interaction with the substrate (compare TS-R6 and TS-R9 structures in Figure 6).

Figure 6. B3LYP/6-31G(d) geometries of the disfavoured TSs for catalyst 6 and 9. In the "balls and springs" pictures, the COOMe groups of the Hantzsch ester are reported in "transparent" fashion; non-participating hydrogens are omitted for clarity.
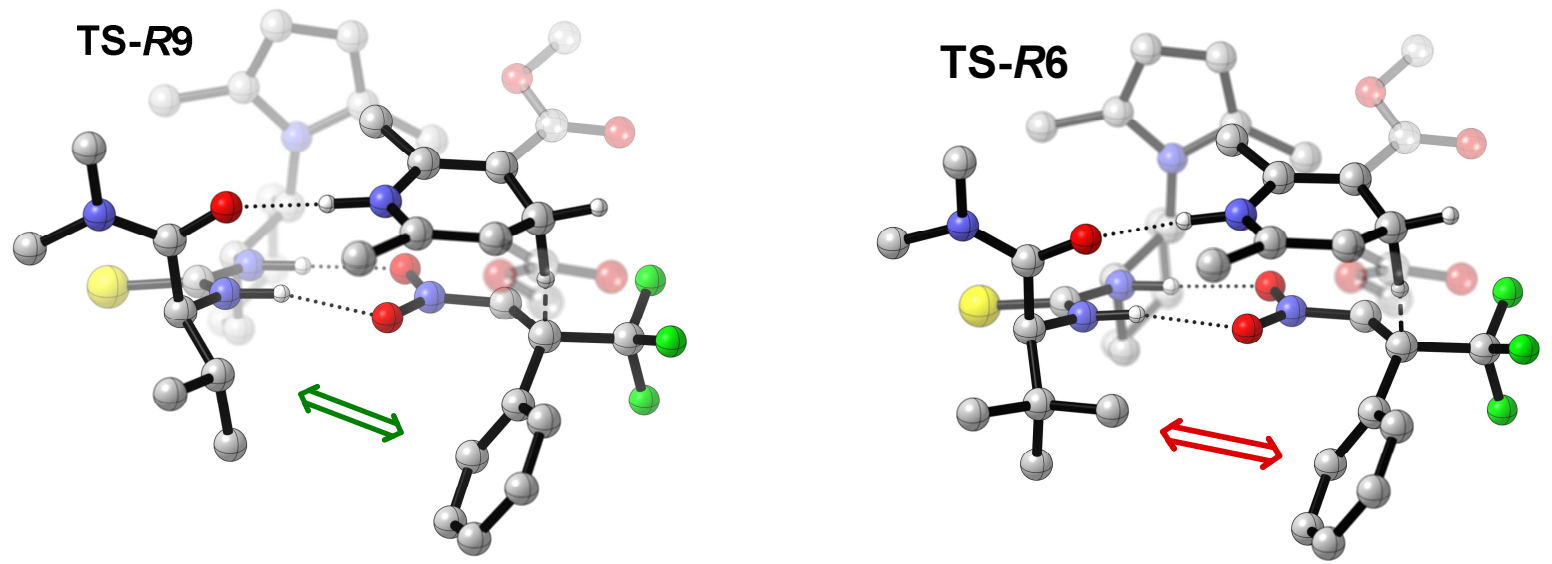

In the attempt to rationalize the higher ee observed in the reduction of alkyl substituted nitroalkenes it was noticed that in the disfavoured TSs the methyl group of the 2,5-dimethyl pirrole moiety is forced toward the $\beta$-substituent of the substrate. Therefore, when such a substituent is an 
aryl group, a $\mathrm{CH}_{3}-\pi$ interaction might take place, reducing the energy difference between favoured and disfavoured TSs. ${ }^{[24]}$

The presence of this kind of interaction was confirmed performing a Non Covalent Interaction (NCI) analysis, as previously reported by Yang et al., using the NCIPLOT software; ${ }^{[25]}$ results are shown in Figure 7. The green surface between the phenyl ring and the catalyst's methyl substituent evidences a large region of weak positive interaction due to the expected $\mathrm{CH}_{3}-\pi$ stacking. Clearly, when the $\beta$-aryl group is replaced by an alkyl one, this interaction cannot occur. Hence, TSs leading to the $R$ and $S$ enantiomer should be energetically more differentiated, justifying the experimentally observed higher enantiomeric excesses with alkyl derivatives (entries 6 and 7 of Table 3).

Figure 7. NCIPLOT analysis performed in a selected cube (see supporting information) using the M06-2X/6-311+G(2df,2pd) electron density calculated on the B3LYP/6-31G(d) geometry of the disfavoured TS for catalyst 9. Non-participating hydrogens are omitted for clarity.

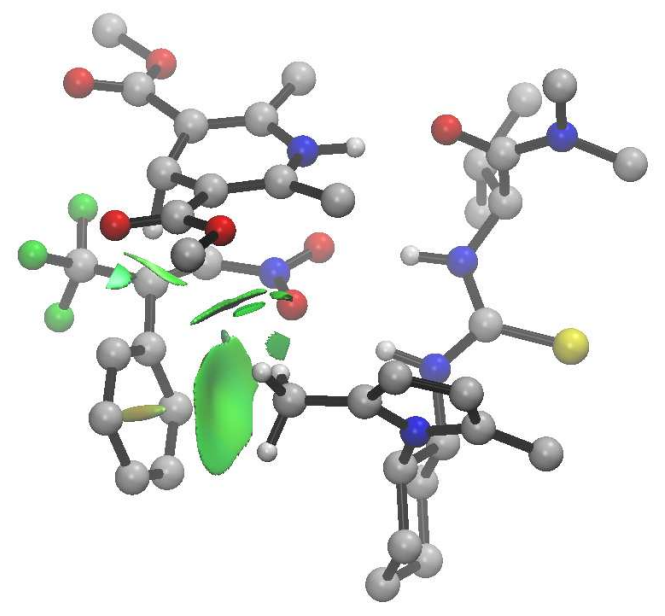

The calculated Gibbs free energies and the prediction of the enantioselectivities are reported in Table 5. Since the B3LYP functional is known to give a poor description for long-range dispersive interactions, as expected, a better prediction of the enantiomeric excesses was obtained with M06-2X. In particular, a remarkably good agreement between calculated and experimental e.e. obtained with catalyst 6 has been achieved with M06-2X (43\% vs. 57\% e.e.). Noteworthy, both the DFT functionals predict higher TSs energy differences for catalyst $\mathbf{9}$ compare to $\mathbf{6}$, thus confirming the valine-derivative 9 to be the best performing catalyst. [26]

Table 5. Computationally determined energies and enantioselectivities. 


\begin{tabular}{|c|c|c|c|c|c|}
\hline & \multicolumn{2}{|c|}{ B3LYP } & \multicolumn{2}{|c|}{ M06-2X } & \multirow{2}{*}{$\begin{array}{c}\text { Exp. e.e. } \\
(\%)^{\mathrm{c}}\end{array}$} \\
\hline & $\Delta \Delta \mathrm{G}^{\mathrm{a}}$ & e.e. $(\%)^{\mathrm{c}}$ & $\Delta \Delta G^{\mathrm{b}}$ & e.e. $(\%)^{\mathrm{c}}$ & \\
\hline $\begin{array}{l}\text { TS-R6 } \\
\text { TS-S6 }\end{array}$ & $\begin{array}{l}0.0 \\
2.4\end{array}$ & 97 & $\begin{array}{l}0.0 \\
0.5\end{array}$ & 43 & 57 \\
\hline $\begin{array}{l}\text { TS-R9 } \\
\text { TS-S9 }\end{array}$ & $\begin{array}{l}0.0 \\
4.6\end{array}$ & $>99$ & $\begin{array}{l}0.0 \\
3.0\end{array}$ & 99 & 81 \\
\hline
\end{tabular}

${ }^{a} \Delta \Delta G$ in $\mathrm{kcal} / \mathrm{mol}$ at the B3LYP/6-311+G(2df,2pd)//B3LYP/6-31G(d) level of theory. The thermal correction to the Gibbs free energy was calculated at the B3LYP/6-31G(d) level; ${ }^{b} \Delta \Delta G$ in $\mathrm{kcal} / \mathrm{mol}$ at the $M 062 X / 6-311+G(2 d f, 2 p d) / / B 3 L Y P / 6-31 G(d)$ level of theory. The thermal correction to the Gibbs free energy was calculated at the B3LYP/6-31G(d) level; ${ }^{c}$ e.e. was calculated according to the formula: e.e. $=100 \exp \left[-\left(\Delta \Delta G_{S}\right) / R T\right]$

In conclusion, the enantioselective organocatalytic reduction of $\beta$-trifluoromethyl nitroalkenes was successfully accomplished, either on $\beta$-aryl- or $\beta$-alkyl substituted substrates, in up to $97 \%$ e.e.. The stereochemical outcome of the reaction and the behaviour of the metal-free, thiourea-based catalyst were also rationalized and discussed, based on computational studies and DFT transition states analysis. This easy to perform methodology offers a valuable entry for a straightforward synthesis of enantiomerically pure $\beta$-trifluoromethyl amines. [27]

\section{Experimental Section}

\section{General Methods}

All commercially available reagents including dry solvents were used as received. Organic extracts were dried over sodium sulfate, filtered, and concentrated under vacuum using a rotatory evaporator. Nonvolatile materials were dried under high vacuum. Reactions were monitored by thin-layer chromatography on pre-coated Merck silica gel 60 F254 plates and visualized either by UV or by staining with a solution of cerium sulfate (1g) and ammonium heptamolybdate tetrahydrate $(27 \mathrm{~g})$ in a mixture of water $(469 \mathrm{~mL})$ and concentrated sulfuric acid $(31 \mathrm{~mL})$. Flash chromatography was performed on silica gel 60. The NMR spectra were obtained at $300 \mathrm{MHz}$ for ${ }^{1} \mathrm{H}-, 75 \mathrm{MHz}$ for ${ }^{13} \mathrm{C}-$, and $282 \mathrm{MHz}$ for ${ }^{19} \mathrm{~F}-\mathrm{NMR}$ on a Bruker 300 spectrometer.

$\underline{\text { General procedure for organocatalytic reactions }}$ 
The $\beta$-trifluoromethyl nitroalkene derivative ( 1 eq.) and the catalyst ( 0.1 eq.) were dissolved in the dry solvent (1M solution) under nitrogen atmosphere for 10 minutes at the desired temperature; Hantzsch ester (1 eq.) was added as a solid and the mixture stirred for 20 hours at constant temperature. The solvent was then removed under reduced pressure and products were isolated by flash column chromatography on silica gel (hexane:ethyl acetate) for their NMR characterization. When low-boiling substrates were employed - yielding low boiling products - only the crude mixture was analyzed. Enantiomeric excess was determined by HPLC on chiral stationary phase.

Supporting Information. Experimental details for catalysts synthesis, catalytic enantioselective reductions and synthetic modification for the absolute configuration determination. Analysis and characterization, NMR and HPLC traces of the reaction products. Cartesian coordinates, total electronic and Gibbs free energies of all reported structures.

Acknowledgements. M. B. thanks COST action CM9505 "ORCA" Organocatalysis and ZaCh Systems (Zambon Group) for financial support. E.M. and M.O. thank Universita' degli Studi di Milano for PhD fellowships, S.R. thanks Universita' degli Studi di Milano for post-doctoral fellowship.

\section{References and Notes}

[1] a) P. Kirsch, Modern Fluoroorganic Chemistry: Synthesis, Reactivity, Applications, WileyVCH, Weinheim, 2013; b) I. Ojima, Fluorine in Medicinal Chemistry and Chemical Biology, Wiley-Blackwell, Chichester, 2009; c) J.- P. Beguè, D. Bonnet-Delpon, Bioorganic and Medicinal Chemistry of Fluorine, Wiley-VCH, Hoboken, 2008; d) S.Purser, P. R. Moore, S. Swallow, V. Gouverneur, Chem. Soc. Rev., 2008, 37, 320-330; e) K. Muller, C. Faeh, F. Diederich, Science 2007, 317, 1881-1886.

[2] H.-P. Chiu, B. Kokona, R. Fairman, R. P. Cheng, J. Am. Chem. Soc., 2009, 131, 1319213193; d) B. C. Buer, J. Chugh, H. M. Al- Hashimi, E. N. G. Marsh, Biochemistry, 2010, 49, 5760-5765; e) C. R. Hopkins, ACS Chem. Neurosci., 2012, 3, 3-4.

[3] Review: J. Nie, H.-C. Guo, D. Cahard, J.-A. Ma, Chem. Rev., 2011, 111, 455-529. See also: D. Cahard, V. Bizet, Chem. Soc. Rev., 2014, 43, 135-147.

[4] A. Genoni, M. Benaglia, E. Massolo, S. Rossi, Chem. Commun., 2013, 49, 8365-8367.

[5] a) Y.- F. Wang, G. Hervè Lonca, S. Chiba, Angew. Chem. Int. Ed., 2014, 53, 1067-1071; b) H. Egami, S. Kawamura, A. Miyazaki, M. Sodeoka, Angew. Chem. Int. Ed., 2013, 52, 78417844; c) E. Kim, S. Choi, H. Kim, E. J. Cho, Chem. Eur. J., 2013, 19, 6209-6212. 
[6] E. Obijalska, G. Mloston, A. Six, Tetrahedron Lett., 2013, 54, 2462-2465.

[7] a) D. A. Nagib, M. E. Scott, D. W. C. MacMillan, J. Am. Chem. Soc., 2009,131, 1087510877; b) A. E. Allen, D. W. C. MacMillan, J. Am. Chem. Soc., 2010, 132, 4986-4987.

[8] Y. Yasu, T. Koike, M. Akita, Org. Lett., 2013, 15, 2136-2139.

[9] M. Molteni, M. C. Bellucci, S. Bigotti, S. Mazzini, A. Volonterio, M. Zanda, Org. Biomol. Chem., 2009, 7, 2286-2296 and references cited therein.

[10] O. Andrey, A. Alexakis, A. Tomassini, G. Bernardinelli, Adv. Synth. Catal., 2004, 346, $1147-$ 1168.

[11] F.-L. Liu, J.-R. Chen, B. Feng, X.-Q. Hu, L.-H. Ye, L.-Q. Lu, W.-J. Xiao, Org. Biomol. Chem., 2014, 12, 1057-1060.

[12] Q. Chen, G. Wang, X. Jiang, Z. Xu, L. Lin, R. Wang, Org. Lett., 2014, 16, 1394-1397.

[13] J.-R. Gao, H. Wu, B. Xiang, W.-B. Yu, L. Han, Y.-X. Jia, J. Am. Chem. Soc., 2013,135, 2983-2986.

[14] Y. Zhao, X.-J. Wang, Y. Lin, C.-X. Cai, J.-T. Liu, Tetrahedron, 2014, 70, 2523-2528.

[15] N. J. A. Martin, L. Ozores, B. List, J. Am. Chem. Soc., 2007, 129, 8976-8977. For a recent organometallic-catalyzed nitroalkene reduction with Hantzsch ester see: L.-A. Chen, W. Xu, B. Huang, J. Ma, L. Wang, J. Xi, K. Harms, L. Gong, E. Meggers, J. Am. Chem. Soc., 2013, 135, 10598-10601. For other contributions in the field see: J. F. Schneider, F. C. Falk, R. Fröhlich, J. Paradies, Eur. J. Org. Chem., 2010, 2265-2269 and J. F. Schneider, M. B. Lauber , V. Muhr, D. Kratzer, J. Paradies, Org. Biomol. Chem., 2011, 9, 4323-4327.

[16] For experimental details on the synthesis and characterization of the catalysts see the Supporting Information.

[17] S. G. Ouellet, A. M. Walji, D. W. C. MacMillan, Acc. Chem. Res., 2007, 40, 1327-1339.

[18] For a recent review on enantioselective potonation see: S. Oudeyer, J.-F. Brière, V. Levacher, Eur. J. Org. Chem., 2014, 6103-6119. For important contributions in the field see also: D. Leow, S. Lin, S. K. Chittimalla, X. Fu, C.-H. Tan, Angew. Chem. Int. Ed., 2008, 47, 56415645 and S. Lin, D. Leow, K.-W. Huang, C.-H. Tan, Chem. Asian J., 2009, 4, 1741-1744.

[19] For a recent example of an enzymatic stereoselective reduction of $\alpha$-methylated transnitroalkenes see: E. Burda, T. Reß, T. Winkler, C. Giese, X. Kostrov, T. Huber, W. Hummel, H. Gröger, Angew. Chem. Int. Ed., 2013, 52, $9323-9326$.

[20] In fact, a change in the diastereoisomeric ratio of the two isomers, from roughly 50:50 to 90:10 was observed for all compounds 16a-c to take place in few days, even when the isomeric mixture was kept neat at $8{ }^{\circ} \mathrm{C}$. 
[21] D. A. Nagib, M.E. Scott, D. W. C. MacMillan, J. Am. Chem. Soc,. 2009, 131, 10875-10877. The reactions sequence did not affect the stereochemical integrity of the starting material, as confirmed by HPLC analysis on chiral stationary phase (see Supporting Information).

[22] (a) A. D. Becke, J. Chem. Phys. 1993, 98, 5648-5652. (b) C. Lee, W. Yang, R. G. Parr, Phys. Rev. B 1988, 37, 785-789. (c) P. J. Stephens, F. J. Devlin, C. F. Chabalowski, M. J. Frisch, J. Phys. Chem. 1994, 98, 11623-11627.

[23] Y. Zhao, D. G. Truhlar, Theor. Chem. Acc., 2008, 120, 215-241.

[24] We thank one referee for giving the nice suggestion to consider also this type of interaction.

[25] (a) E. R. Johnson, S. Keinan, P. Mori-Sànchez, J. Contreras-García, A. J. Cohen and W. Yang, J. Am. Chem. Soc., 2010, 132, 6498-6506; (b) J. Contreras-García, E. R. Johnson, S. Keinan, R. Chaudret, J.-P. Piquemal, D. N. Beratan and W. Yang, J. Chem. Theory Comput., 2011, 7, 625-632.

[26] For further details on the computational studies see the Supporting Information.

[27] For a recent contribution on the synthesis of chiral trifluoromethyl amines see: X. Dai, D. Cahard, Adv. Synth. Catal., 2014, 356, 1317-1328. See also: S. J. Shaw, D. A. Goff, L. A. Boralsky, M. Irving, R. Singh, J. Org. Chem., 2013, 78, 8892-8897. For a discussion on the unique features of $\beta$-fluroamines see: L. E. Zimmer, C. Sparr, R. Gilmour, Angew. Chem. Int. Ed., 2011, 50, 11860-11871. 


\section{Graphical Abstract}

An efficient organocatalytic stereoselective reduction of $\beta$-trifluoromethyl-substituted nitroalkenes, mediated by 3,5-dicarboxylic esters-dihydro pyridines (Hantzsch ester type), has been successfully developed. A thiourea-based $(S)$-valine derivative promoted the reaction in up to $97 \%$ e.e., affording immediate precursors of enantiomerically enriched $\beta$-trifluoromethyl amines.

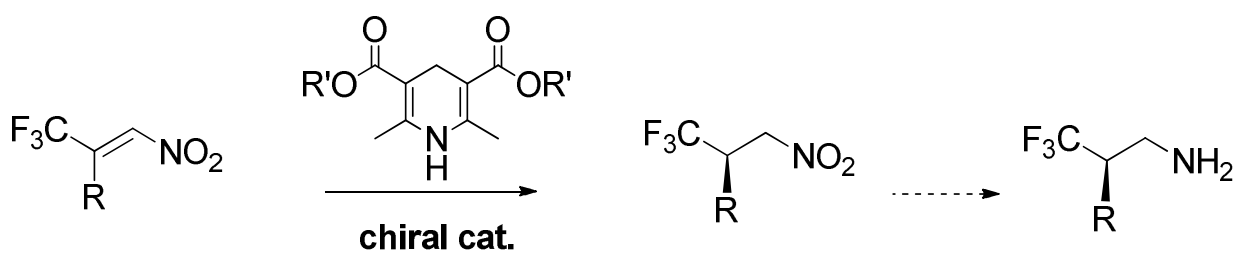

